\title{
Study of Practice Teaching Reform of Design Color
}

\author{
Lin Xiao ${ }^{1}$ \\ ${ }^{1}$ Jiangxi Institute of Fashion Technology, Nanchang, Jiangxi, 330201
}

KEYWORDS: Color Design; Teaching Reform; Exploration

\begin{abstract}
With the rapid development of China's education, higher education in the new period put forward higher requirements. As a basic course of art and design students to learn, Color design has a great impact on the development of students. However, the current design of color has been many problems in the teaching process, the impact on students of color perception and skills. This paper explores color design teaching reform practice and makes concrete reform measures.
\end{abstract}

\section{Introduction}

Nature of the College of Art and Design professional curriculum design and color design sketch course there are many similarities, are designed to help students of art and design foundation course, also change the past, students have learned in the college entrance examination training sketches and color and breakthroughs [1]. However, China's current design color teaching too much emphasis on students to explain color theory, taking mode of teaching and training, all of which affect the students related capacity, resulting in a number of art and design students after graduation into society difficult employment phenomenon. Therefore, the color design education reform has become a top priority.

\section{Teaching Content and Features Design Color}

In the context of continuous development of society, people of art and design majors are increasingly high requirements, today's traditional colors and color design has a very different, both in terms of connotation, the traditional color content contained more single , and now color design contains a figurative design color abstract design color, design color and other imagery. Color design as an art and design students to learn an important course in the actual teaching process should focus on the students of color perception and skills.

Teachers through the rational planning of color design courses, in the early stage mainly for students on the color structure, to help students understand and master the color hue, lightness, purity, passage of such concepts, and the relationships between them, the same time, in the process of teaching students but also rich with color capability, aim to help students better understand and apply relevant content knowledge in teaching in the later stages.

\section{Design Color Teaching Reform Measures}

In the previous design color teaching process, many newly enrolled students affected by school colors, color design of this course often need to invest a lot of time to adapt and accept. Because the color process of teaching students the college entrance examination before, the teacher arranged for students of classroom exercises, homework, teaching activities in relative terms are for entrance and expanded, so that students learn knowledge and observation of the world, to experience life the 
formation of a antithesis, and the color of teaching high school students rarely involves imagination and creativity [2]. Therefore, many newly enrolled students that they will produce a confused feeling, teachers should detail the content of teaching the basics of color design of this course, so that students can help students in this course design color awareness and teachers in the teaching process should also be through classroom exercises, homework, teaching activities, highlighting the differences between the color design color and high school, and this will help students to better understanding and faster color design of this course and master knowledge. On the other hand, many schools have entrance exams art and design professionals to examine the students 'skills, the main purpose of style, so the process of color teaching reform, should pay attention to cultivate students' creativity and imagination, as well as their ability to express emotion and unique creative thinking, so that it can help improve students' ability to use color.

In the previous design color teaching process, teachers explain too much emphasis on book knowledge, which limits the students' creativity and imagination. In response to this situation, teachers should develop students' horizons, the use of spare time on a number of international masters parsing after parsing is complete, then the rational use of these works to the teaching process, such as: teachers can Mondrian Ann, Matisse, Chagall, Monet and other masters for analysis, then these works reasonably into the design color classroom for students to understand the masterpieces of style, characteristics, skills, which will help to enhance students understanding of art and improve their aesthetic ability [3]. Color possess emotive factors are very unique inside the entire visual arts, nature seasons landscape, emotions and other people's lives, they are able to use color to express. In addition, it should be disposed of students from concrete to abstract color training teachers need in-depth exploration of oriental art thinking intuition, perception and modern Western painting expressionism artistic thinking, so as to ensure the reasonableness of color training to help student self-breakthrough in the process of subjective expression, enrich students' imagination and creativity to achieve the purpose.

In the previous design color teaching process, teachers explain too much emphasis on book knowledge, ignoring the importance of interactive sessions, many students doubts arising in the learning process does not get appropriate treatment, resulting in the quality of teaching this course design color difficult to improve. Whether teaching the subject, we need to mobilize the enthusiasm of the students to be able to achieve good learning outcomes [4]. Color design teaching, too, to strengthen the teaching process interactive sessions, can help teachers understand the students learning deficiencies, and thus targeted guidance to the students' abilities in all aspects of effectively improve, for example: teacher in teaching the "sketch" the knowledge, first, arrange for students after school prep tasks, which will help the students through various channels to understand the relevant information; secondly, in the classroom, because students have spare time to sketch this knowledge was a certain understanding, teachers can take the form of questions to mobilize the enthusiasm of the students, "What sketch that?" "learning sketch what is the point?" and so this type of problem, allow students to start thinking, at this point, the teacher should be left to the students ample time after the students finishing their point of view is complete, and then select the students to discuss perspectives, teachers should carefully analyze the student's answer, reasonably identify shortcomings, and in the classroom lectures in this knowledge points to explain in detail; Finally, teachers should also be reasonable for students with after-school practice, this will help students to enhance students' understanding and application of knowledge.

The influence of traditional color design practices, students during working too much emphasis on work, ignoring the grasp of color relationships, and students in the creative process requires a lot of vision and energy to work, which students design color is unfavorable. With the continuous 
development of computer technology, has penetrated into people's lives and work, for people to bring a lot of convenience, color design practices should be reasonably combined with computer technology, so not only can improve the students' design colors interest in the use of computer software also enables students to work richer, more specifically [5]. For example: When the student goes brightness during practice, if the use of traditional practices were hand-drawn, all students need to color lightness desired relationship is modulated during the filling process once one color runs out, it is difficult to modulation of the same color, but also to prepare students midway pigment breaks the students' thinking inspiration, which is the creation of the students brought a great impact. Innovation of practices, a reasonable choice of computer graphics software for the job, not only can reduce the time and effort put into the student can also modify any color in a short time, and will not have any adverse impact of the works. Of course, the use of computer software creation is not absolute and the teacher should be reasonable arrangements depending on the situation.

\section{Conclusion}

In summary, the design color art and design students to learn a basic course, have a great impact on the development of students, the process of reform and the current practice of teaching design color is also exploring the proposed emphasis on design color and color differences between high school; expand their horizons and learn; to strengthen the teaching process interactive sessions; and innovative ways to work these few suggestions, hoping to offer some suggestions for the design of color Teaching.

\section{Reference:}

[1] Zhang Yan. Higher Colleges Environmental Art Design Color Composition Teaching Reform [J] Art and Science, 2014,01: 332.

[2] Men Chao. Higher Colleges graphic design professional "color composition" Exploring Teaching Reform [J]. Nanning Vocational and Technical College, 2014,04: 67-69.

[3] Xing Weijin. dress colors the teaching model based information design concept [J]. Arts Education, 2014,09: 142.

[4] Chen Li. base color course how best to undertake teaching practice courses designed to explore [J]. Art and Science, 2015,04: $236+264+213$.

[5] Li Yuan, Li Qing, Wu Kuaijie. experimental design and data processing" Practice and Exploration of Teaching Reform [J]. Education Forum, 2015,25: 158-159. 